\title{
Tutoramento entre pares e integração universitária da deficiência
}

Resumo: O estudo analisa a relação entre tutor e tutorado com deficiências no contexto universitário. A hipótese de pesquisa é que o método do tutoramento entre pares poderá facilitar a integração dos estudantes universitários com deficiências e que a compartilha dos problemas e as paritárias condições de partida do tutor e do tutorado ajude os mútuos processos de socialização. Vinte tutores preencheram um questionário elaborado ad hoc, e o corpus narrativo foi submetido a uma análise textual. Os resultados evidenciam o fato do tutoramento entre pares ser uma metodologia percidônea para o desenvolvimento de uma mútua relação de competências, no âmbito de uma relação afetiva e simétrica; isso permite ultrapassar a perspetiva assistencial relativa à deficiência, incita o tutorado a "ultrapassar a si próprio", facilitando a sua aprendizagem e assim ativando a sua "zona de desenvolvimento proximal".

Palavras-chave: Relações sociais. Integração. Tutoramento entre pares.

\section{Introdução}

O presente estudo explora, em vários níveis de análise, a relação entre tutor e tutorado com deficiência, num específico contexto social e cultural. O trabalho de pesquisa aqui apresentado tem como estrutura teórica a psicologia social e cultural. Referimo-nos nomeadamente às contribuições da escola histórico-cultural de Vygotskij (1934), da psicologia social e cultural de matriz socioconstrutivista (ANOLLI, 2005; BERGER; LUCKMAN, 1966; BRUNER, 1990; COLE, 1996; GERGEN, 1995; SMORTI, 1997, 2003) e aos estudos sobre a integração da deficiência (SHIMA, RODRIGUES, 2009; WYNNE, MCANANEY, 2010; ZORFASS, 1994).

De acordo com Vygotskij (1934), o desenvolvimento está ligado às situações educativas e de aprendizagem vividas pelo indivíduo. Esse, apresenta-se como uma consequência das aprendizagens às quais o indivíduo é submetido. De fato, o desenvolvimento não precede a aprendizagem, pelo contrário, representa a sua causa. Fica claro que Vygotskij atribui uma especial importância às interações sociais, pois é nestas que se originam as funções mentais superiores. A ontogênese dos processos mentais superiores - tais como o raciocínio, o pensamento lógico-abstrato etc. - acontece duas vezes, primeiramente no nível social e, sucessivamente, no nível intrapessoal. A linguagem, por exemplo, transforma-se em comunicação, no nível social (interpessoal), em pensamento, no nível intrapessoal. Nesta perspectiva, o conjunto das relações
Giulia Savarese Universidade de Salerno gsavarese@unisa.it

Oreste Fasano Universidade de Salerno ofasano@unisa.it

Monica Mollo Universidade de Salerno mmollo@unisa.it

Nadia Pecoraro Universidade de Salerno npecoraro@unisa.it 
(e comunicação) vividas pelo indivíduo, permite-lhe agir na sociedade, modificando a sua atitude, e ajudando-o a adaptar-se constantemente. Os processos e as categorias mentais são mediados por dispositivos (artefatos culturais) pré-existentes naquela dada sociedade e naquele específico momento histórico; são o fruto da cultura e da história, pois o indivíduo, apropriando-se delas, conhece aquela história e aquela cultura, agindo como membro de uma dada sociedade. A ação será sempre e de qualquer forma mediada pelos instrumentos culturais, pois: "[...] a natureza psicológica do ser humano representa o conjunto das relações sociais transportadas no interior e que se tornaram funções da personalidade e formas da sua estrutura" (VYGOTSKIJ, 1934, p. 202). Nesse sentido, a qualidade das aprendizagens às quais o indivíduo é submetido permite a ativação daquela que Vygotskij define como Zona de Desenvolvimento Proximal (ZDP), entendida como "[...] a diferença entre o nível de resolução dos problemas sob a direção e com a ajuda do adulto (ou de crianças mais competentes) e o nível atingido sozinhas" (VYGOTSKIJ, 1934, p. 108). O próprio Bruner (1983) concebia o desenvolvimento como progressivo cumprimento, por parte da criança, das suas potencialidades, afirmando que a natureza deste desenvolvimento é essencialmente social. De fato, por meio da interação com a mãe, a criança adquire progressivamente o sistema simbólico cultural de referência a fim de conhecer e representar a si mesmo e a realidade. O indivíduo interioriza o sistema cultural do qual faz parte, formado por símbolos, crenças, concepções e valores, que têm um significado e que são transmitidos de geração em geração, e a linguagem representa o instrumento que permite ao indivíduo conhecer, interpretar e negociar os significados da realidade (BRUNER, 1990). A partir deste constante processo de interpretação da realidade, do Eu e dos outros, os indivíduos constroem o seu conhecimento do mundo. De acordo com Bruner (1975), o pensamento narrativo permite criar uma relação de interdependência entre o cenário da ação e o cenário da consciência, formando assim o próprio processo da construção da identidade (ERIKSON, 1968), que se explica concretamente pelas interações sociais, interiorizando as experiências interpessoais e ativando todos os níveis de funcionamento mental na construção da personalidade (VYGOTSKIJ, 1934). Em conclusão, Bruner tenta compreender como os indivíduos, em relação a outras realidades, elaboram o seu próprio mundo e como, por meio de trocas de 
significado com os outros, constroem o seu próprio significado e a sua própria experiência.

A partir destes pressupostos, fica claro que a construção do conhecimento, por parte do indivíduo, é fruto da qualidade das interações por este instauradas, que se estendem através do uso de artefatos que o ambiente e a cultura oferecem e que guiam a atividade dos indivíduos. A dimensão sociocultural, portanto, contribui para a determinação das escolhas profissionais, a própria organização do trabalho e, de forma complementar, para a modelação do contexto no qual se desenvolvem as atividades (GERGEN, 1995; SALVATORE et al., 2003). O conhecimento, portanto, encontra-se contextualizado como resultado de significados produzidos pelos indivíduos e da capacidade destes em partilhar estes significados, crenças, valores e atividades. Em conclusão, parece essencial no nível metodológico uma explícita referência à dimensão narrativa e culturalista (BRUNER, 1990, 2010; DEMETRIO, 2003; IANNACCONE, SMORTI, 2009; SMORTI, 1997) enquanto modalidade por meio da qual os indivíduos organizam, atribuem sentido e comunicam/ partilham a sua própria experiência e interpretação da realidade.

\section{Relação entre pares e integração da deficiência na universidade}

A integração social da pessoa com deficiências tem a ver com os diferentes campos de expressão da própria pessoa: o relacional (ser acolhido, desenvolver verdadeiros papéis sociais e profissionais, amizades, colaborações etc.), mas também o cognitivo (aprender coisas novas, aprender a pensar, a resolver problemas, desenvolver novas capacidades e competências determinadas pelas peculiares necessidades do sujeito em dificuldade e pelas finalidades do ambiente social) e psicológico (crescer na autoestima, na autoeficácia, na identidade, na expressão das emoções) (IANES, 2000). A integração universitária coloca-se neste contexto. Na Itália foi aprovada a Lei $n^{\circ} 17 / 99$, que introduziu um sistema organizativo mais centrado no estudante universitário com deficiências, por exemplo, através da instituição da tutoramento entre pares ou de tutoramento especializado, bem como a facilitação dos exames, e ainda pelo uso de equipamentos adequados (PARLAMENTO ITALIANO, Legge 17/1999).

revista entreideias, Salvador, v. 2, n. 2, p. 201-216, jul./dez. 2013203 
As relações que se instauram entre os estudantes universitários "normais" e os colegas com deficiências são geralmente caracterizadas por níveis de disponibilidade e aceitação mais consistentes daqueles que se observam, na maioria das vezes, no ensino básico e no ensino médio, embora pareçam existir diferenças significativas entre as várias faculdades: os estudantes das faculdades humanísticas, por exemplo, mostram em geral a tendência para assumir atitudes mais favoráveis do que aquelas dos estudantes das faculdades científicas. Todavia, também no nível de vida universitária, existem pesquisas que parecem indicar como os estudantes "normais" experimentem níveis de tensão mais consistentes ao se relacionarem com os colegas com deficiências e, tendo a oportunidade de escolher entre uma interação com um colega com deficiências ou um colega de estudos normal, tenham uma definida tendência a privilegiarem a segunda.

Acerca da atitude dos professores existem antes de mais nada poucas pesquisas: estas parecem porém indicar a presença de atitudes moderadamente favoráveis à frequência universitária dos estudantes com deficiências, embora esta possibilidade tenda a ser questionada ao se verificarem contatos frequentes e "aproximados", como se os professores achassem que a integração seria mais fácil em outros departamentos ou cursos de graduação.

As atitudes manifestadas pelos estudantes universitários com deficiências também não aparecem claramente nas pesquisas até agora efetuadas: uma parte deles tende a minimizar os problemas ligados à deficiência e parece, sobretudo, esperar conseguir "passar despercebido"; outros acham ter observado, em relação a si próprios, sobretudo atitudes negativas, embora afirmem ter muitos amigos entre os colegas "normais" e se sentir perfeitamente à vontade com eles. Apesar do que foi afirmado até agora, muitos estudantes com deficiências acham que a qualidade da sua integração universitária é demasiadamente condicionada pelo juízo dos estudantes, pelo tipo de conhecimento que estes têm, pelos problemas ligados à deficiência e pela quantidade de "isolamento" que de fato muitas vezes eles experimentam.

No que diz respeito à integração dos deficientes na universidade, podem ser propostas seguintes ideias. Considera-se importante a difusão, também entre os estudantes universitários, de uma correta cultura das deficiências, pois as suas atitudes também seriam influenciadas por preconceitos e estereótipos. O aumento dos 
contatos entre estudantes com e sem deficiências, aliado a uma informação adequada, em geral é considerada suficiente para reduzir os problemas de integração social dos deficientes, desde que estes sejam estruturados de maneira a basearem-se na recíproca ajuda (SORESI, 1998, p. 183-184).

Nos processos de integração das deficiências, o tutoramento entre pares (GORDON, 2005), como método no qual um tutor "ensinado", que faça parte do mesmo grupo social (por exemplo, como neste caso, de estudantes universitários da mesma Faculdade) apoia, nos processos de aprendizagem, um tutorado "novato", parece ser particularmente produtivo, melhorando nos estudantes com deficiências a autoestima, as capacidades sociais, o locus de controle. Esta relação, que deve se basear numa interdependência entre os membros (FLACHIKOV, 2012), é capaz de influenciar também a motivação dos tutorados, bem como o empoderamento do tutor e do tutorado (COLVIN, 2007; PARKIN; MCKEGANY, 2000).

\section{Hipóteses e objetivos}

A hipótese de pesquisa traduz-se na ideia que o método de tutoramento entre pares poderá facilitar a integração dos estudantes universitários com deficiências. Além disso, esperamos que o compartilhamento dos típicos problemas universitários e as condições paritárias iniciais dos tutores e dos tutorados ajudem os processos mútuos de socialização. A nossa atenção concentrou-se na relação entre tutor e tutorado com deficiências nos seus aspetos emotivo-afetivos, de socialização e de sucesso/insucesso universitário, assim como evidenciada pelas narrações de uma parte dos protagonistas da relação em objeto, isto é, os tutores.

\section{Participantes e metodologia}

Participaram, na pesquisa, 20 tutores da Universidade de Salerno. Ao fim dos seis meses de atividade de tutoramento entre pares, os tutores foram submetidos a uma entrevista semiestruturada elaborada ad hoc, baseada na elaboração da entrevista narrativa (BRUNER, 1991; SMORTI, 1997). A entrevistas consistiam em cinco perguntas abertas. Todas as entrevistas foram gravadas em áudio e posteriormente transcritas. 


\section{Processos de análise}

A pesquisa adotou uma modalidade de análise quanti-qualitativa, baseada na interpretação das modalidades de resposta dos participantes. As entrevistas foram transcritas, protocoladas e reunidas num único corpus textual. Algumas palavras do texto, tais como os nomes, foram substituídas por palavras-chave como: Estudante_deficiente e Referente_às_deficiências. Este corpus foi submetido a uma análise textual por meio do software "T-lab 5.5" (LANCIA, 2005). Em particular, foi realizada uma Análise dos núcleos temáticos, que permite construir e explorar uma representação dos conteúdos do corpus, a partir da análise de um conjunto de contextos elementares (frases, parágrafos ou textos breves) caraterizados pelos mesmos patterns/padrões de palavras.

O output produz uma tabela de palavras que, dentro das unidades lexicais, co-ocorrem entre elas de acordo com o índice estatístico do chi-quadro, extrapolando as narrações que definem o núcleo temático.

\section{Resultados}

Os resultados apresentam os núcleos temáticos, assim como foram intepretados a partir das palavras ligadas uma à outra, juntamente com alguns textos narrativos relativos aos síngulos núcleos.

A análise das narrações evidenciou a presença de quatro núcleos temáticos partilhados por todas as narrações. Estes têm um peso diferente nas várias narrações (Gráfico 1).

Gráfico 1 - Núcleos Temáticos Partilhados nas Narrações

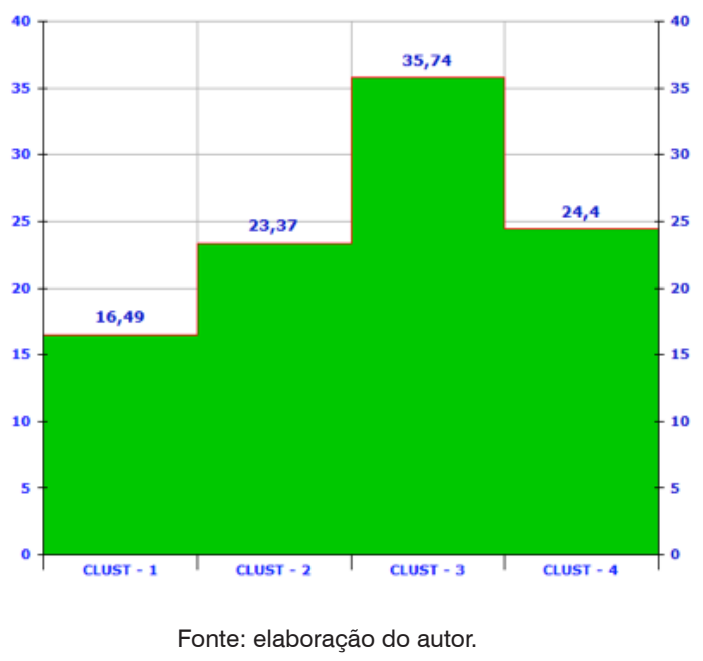




\section{a) Cluster -1: Experiência}

16,49\% das narrações organizam-se em torno deste polo semântico, no qual a palavra "Experiência", que dá o seu nome ao cluster, apresenta o maior número de co-ocorrências.

A atividade de tutoramento por parte dos tutores é vivida como uma "experiência relacional", na qual se estabelece uma ligação, em certos casos amigável, vivida como uma oportunidade de crescimento afetivo, mas não só. Os estudantes acham ter tido, graças a esta relação, a oportunidade de se sentirem mais seguros e responsáveis. Eles, porém, também puderam avaliar a sua capacidade em criar relações com a diversidade, e ainda a capacidade de cumprir um percurso de estudo partilhado, no qual se sentiram mais competentes. Por isso, os tutores querem agradecer o que receberam da experiência, a qual fica assim paritária e simétrica. Na relação aparece um forte componente de "reciprocidade" e desaparece totalmente o caráter de "assistência", que muitas vezes carateriza a relação com uma pessoa deficiente.

Referem-se aqui partes das entrevistas de três tutores:

*sog_2 SCORE (81.167)

Esta experiência permitiu-me também adquirir experiência na área e aplicar tudo o que estudei durante anos, perceber ainda mais como cada sujeito tem as suas próprias caraterísticas, a sua própria experiência de vida ou até um simples método de estudo diferente dos outros sujeitos, e por isso é importante conhecer, compreender, a fim de potencializar da methor forma as capacidades. A ideia de poder ajudar alguém, de funcionar como um apoio, um suporte, mesmo que seja por um curto periodo de tempo, foi uma experiência lindissima que me ajudou a crescer e a melhorar, de fato os estudantes não foram os únicos a ser ajudados, mas eu própria, graças a eles, cresci e ampliei os meus conhecimentos.

*sog_9 SCORE (25.052)

Ao fazer uma análise pessoal das 80 horas efetuadas, só posso sentir-me satisfeita, pois trabalhei num ambiente acolhedor, sereno e sério, com pessoas realmente disponíveis e afáveis que partilharam comigo este percurso. A experiência do tutoramento é uma experiência que toda pessoa deveria ter a possibilidade de viver. Trata-se de uma oportunidade porque é um crescimento não só para quem é ajudado, mas também e, sobretudo, para quem ajuda e segue. Ser tutor enriqueceu-me sob o ponto de vista pessoal, pois

revista entreideias, Salvador, v. 2, n. 2, p. 201-216, jul./dez. 2013207 
vi de perto quanta força de vontade, amor e disponibilidade têm os nossos coetâneos que, infelizmente, não conseguem estudar, gerir os seus momentos de ansiedade e de dificuldade, e ter confiança neles próprios. Estudar com o(a) estudante_com_deficiências foi importante, motivador, surpreendente. Tenho a intenção de continuar a nossa relação de amizade além desta experiência, pois a ligação que nasceu é realmente linda e importante.

*sog_13 SCORE ( 40.837)

Os resultados também foram os mesmos: exame ultrapassado com felicitações. Chegando às minhas conclusões, acho que esta oportunidade é um dos casos singulares que a universidade nos pode oferecer para amadurecer a nossa experiência a nível didático, mas sobretudo a nível humano. Além da usual facilitação da aprendizagem, acho que é importante insistir mesmo na dimensão relacional da atividade, criando uma dinâmica de escuta e de recíproca abertura que tenha todas as caraterísticas de uma verdadeira comunicação empática. A empatia, de fato, é o que nos permite atingir e compreender a experiência vivida pelo outro. Cresci e amadureci muito. Obrigada.

\section{b) Cluster-2: Atividades}

Este núcleo semântico (23,37\%) apresenta-se como articulado e complexo, dispondo seus conteúdos em vários níveis: burocrático/ institucional, organizativo, de conhecimento.

O primeiro nível é definido pelo setting institucional, os estudantes põem a atividade de tutoramento num contexto que tem uma fórmula contratual e umas regras a respeitar (duração, tempos, lugares), e uma Instituição (Faculdade) que desempenha um mandato. Este aspecto é muito importante, pois transmite algumas mensagens explícitas e implícitas nas quais se coconstroem a forma e o conteúdo da relação. A mensagem, por exemplo, poderia ser a de "ajudar" as pessoas com dificuldade. Trata-se de uma relação claramente hierárquica e de vértice.

O segundo nível tem a ver com a organização do grupo de tutoramento com a Referente_às_deficiências. Esta, por um lado media um mandato institucional (Faculdade), por outro assume uma função de contenção, enquanto os próprios tutores vivem uma experiência nova, que os põe à frente dos seus limites e medos, e, portanto, ela estabelece setting facilitador (de ajuda) quer para 
as atividades a serem realizadas, quer para favorecer a primeira forma de contato entre tutor e tutorado.

O terceiro nível tem a ver com o encontro com os deficientes a ser apoiados na atividade de tutoramento entre pares, através de um momento de grupo. Este momento revela-se significativo, a fim de se compreender e planejar as atividades a desenvolver, conhecer os estudantes com deficiências, as suas dificuldades e pedidos, e entrar em contato con os próprios medos e dúvidas acerca desta experiência, num contexto capaz de as acolher e partilhar.

De um ponto de vista sistêmico, o significado do mandato institucional poderia traduzir-se numa delegação, uma grande responsabilidade para os tutores, mas pelo contrário, a atividade organizativa planejada e efetuada com a Referente_às_deficiências permitiu a construção de um significado claro e tranquilizador, sobretudo no que diz respeito à organização das atividades. Neste claro contexto, os tutores, sem se encarregarem de delegações, puderam logo sentir-se em relação paritária entre si e com os tutorados. A possibilidade de efetuar um encontro geral, permitiu criar um grupo de trabalho no qual é exaltada a dimensão do "nós", em vez de uma simples distribuição das atividades. O tutoramento foi fundamental para criar as bases da reciprocidade e para sentir que eram parte de um projeto mais amplo, no qual todos estavam obrigados a meterem-se em discussão e a ultrapassarem as suas dificuldades, através da cooperação e do confronto, melhorando as suas competências. Já não se trata de uma delegação que gera dependência na relação estudante com deficiências-tutor/ tutorado- Referente_às_deficiências.

Acerca deste assunto, alguns dos tutores contam:

*sog_10 SCORE (86.367)

Antes de iniciar as atividades de tutoramento, a Referente_às_ deficiências organizou um encontro entre nós, os tutores, e os estudantes com deficiências interessados nestas atividades. Nesta reunião conhecemos os colegas tutores e os rapazes.[...] Todos os dias, tomei nota das atividades num registo apósito que me foi dado no primeiro dia, juntamente com o contrato. No primeiro dia, depois de termos nos apresentado e falado um bocado sobre nós, nos concentramos na programação de um exame que estava previsto dali em breve.

revista entreideias, Salvador, v. 2, n. 2, p. 201-216, jul./dez. 2013209 
*sog_4 SCORE (73.449)

Ao longo da atividade de tutoramento, a partir do dia 18 de maio até ao dia 17 de setembro de 2010, foi-me atribuída/o a/o estudante_ com_deficiências, inscrita no segundo ano de Ciência da formação da infância e da adolescência. Antes do início da atividade, a nossa coordenadora, a Referente_às_deficiências, marcou um encontro para tentar emparelhar cada estudante com deficiência com um tutor que tivesse um percurso de estudos parecido, de forma a facilitar o apoio e assegurar uma preparação adequada para os exames. Depois deste encontro, a Referente_às_deficiências quis discutir só conosco para nos explicar os pormenores das atividades a serem desenvolvidas, e também preparou o calendário da primeira semana, procurando conciliar as nossas exigências com as dos tutorados.

*sog_16 SCORE (42.221)

A minha atividade de tutor desenvolveu-se no período entre o dia 27 de Maio e o dia 12 de Setembro. Nestes meses apoiei duas estudantes com deficiências. Trabalhar com duas meninas foi ainda mais estimulante e divertido. Uma pessoa se percebe de que elas, como qualquer outro, têm interesses e métodos de estudo diferentes. Elas também encaram as suas deficiências de forma diferente. [...] Quando iniciei este percurso tinha algumas dúvidas e medos, as dúvidas e os medos do costume de quem começa algo de novo e não sabe se vai consegui enfrentar o desafio. Tinha uma grande vontade de me empenhar, mas não sabia bem se teria conseguido deixar algo de bom, quer do ponto de vista material, quer do humano. Acho que os jovens com deficiências devem ter as mesmas dúvidas... conseguirei enfrentar o desafio? O compartilhamento com o grupo dos tutores, porém, tranquilizou-me: não era a única que tinha medos.

c) Cluster -3: Exame

O terceiro núcleo semântico $(35,74 \%)$ tem uma maior importância nas narrações dos tutores e organiza-se em torno da palavra "Exame".

Este núcleo narrativo é muito interessante, pois explicita a modalidade de trabalho através da qual os tutores e os tutorados planejaram as suas atividades, a modalidade de desempenho e os êxitos. 
O planejamento das atividades teve em conta não só aspetos estritamente didáticos e as estratégias de aprendizagem, mas partiu das dificuldades que levam os estudantes com deficiências a ter um insucesso (dificuldade de concentração, mudança de humor, medo).

O tutor, segundo os entrevistados, é uma pessoa que contribui para o desenvolvimento formativo dos estudantes que lhe são entregues, teve uma função de "andaime" (scaffolding) (BRUNER, 1975) para a aprendizagem, através do apoio e o estímulo constante, bem como através da máxima individualização das metodologias de ensino/aprendizagem.

O papel mais importante do planejamento conjunto, todavia, esteve relacionado sobretudo com a possibilidade de compartilhar as causas (cognitivas, emotivas, relacionais e metodológicas) do insucesso no estudo e no desempenho no exame. Esta contextualização eliminou da "deficiência" o rosto do insucesso, restituindo ao tutorado, por meio de instrumentos e metodologias conjuntas, o poder e a responsabilidade do seu percurso de estudos.

Eis a narração de dois tutores:

*sog_17 SCORE ( 23.022)

Só pedi à/ao estudante_com_deficiências que me explicasse as dificuldades que encontrava na preparação para os exames. Ela explicou-me que tinha problemas de compreensão, por isso decidimos ler e explicar em conjunto os textos, ou as partes que ela achava mais difíceis [...] Um dos exames não correu muito bem, as primeiras perguntas foram mesmo sobre o texto que não tínhamos estudado em conjunto e as suas incertezas não lhe permitiram passar no exame. A estudante encarou muito bem esta reprovação, conseguiu racionalizar sem perder a confiança, e eu the fiz notar que de qualquer maneira tinha tido coragem em ter ido fazer o exame e que talvez, agora que tinha aprendido o método, não devia mais cair na desconfiança.

*sog_13 SCORE ( 45.246)

Encontrei pela primeira vez a estudante_com_deficiências no dia antes do seu exame de História Medieval, e ela pareceu-me logo uma menina muito ansiosa e insegura; de fato ela repetia a matéria do exame com muita ansiedade e muitas vezes fechava o livro como se quisesse abandonar. Percebi logo que era uma menina que tinha uma grande necessidade de ser tranquilizada e apoiada.

revista entreideias, Salvador, v. 2, n. 2, p. 201-216, jul./dez. 2013211 


\section{d) Cluster -4: Conceito}

O último núcleo (24,45\% da unidade de contexto) organiza-se em torno da palavra "Conceito".

Diferente do anterior, este evidencia as atividades puramente didáticas realizadas entre tutor e tutorado que são úteis para a aprendizagem, tais como a organização de esquemas, mapas conceituais, repetição, a memorização e a exposição.

Descrevem alguns dos tutores:

*sog_14 SCORE ( 25.179)

O estudante_com_deficiências tem um método de estudo muito eficiente: foi ele quem leu o texto em voz alta e que sublinhou os conceitos-chave; eu limitei-me a apoiá-lo, ouvi-lo e oferecer-lhe explicações sempre que havia conceitos que não the parecessem claros. Cada encontro iniciava antes de qualquer coisa com a exposição oral dos assuntos tratados anteriormente e que o estudante memorizava e repetia ao longo da semana; sucessivamente procedíamos com a leitura do texto, criando depois uns mapas conceituais que the permitiam memorizar e compreender melhor os conceitos mais importantes.

*sog_18 SCORE ( 13.38$)$

No início da minha atividade de tutoria, a estudante_com_ deficiências estava perto de concluir a explicação e a repetição do exame de "Higiene geral e aplicada" e ela, estando habituada a estudar com mapas conceituais, a memorização foi mais fácil e mostrou-se logo capaz de repetir com muita aptidão os assuntos estudados. Sempre procurei que ela repetisse os assuntos tratados ao longo dos encontros anteriores de forma a não perder o fio da conversa, para que ela não esquecesse os assuntos tratados e a fim de treinar a sua memória.

\section{Conclusões}

De acordo com a nossa hipótese, a pesquisa tinha como objetivo analisar, em vários níveis, a relação entre tutor e tutorado com deficiências. Na nossa opinião, num específico contexto social e cultural, através do método do tutoramento entre pares é possível criar um terreno de compartilhamento de significados (BRUNER, 1990) sobre o mundo universitário entre os tutores e os tutorados, 
que poderia favorecer o sucesso e a integração universitária dos estudantes com deficiência. A partir da análise das entrevistas, evidenciaram-se alguns pontos que contribuem para esclarecer o papel que a relação entre os tutores e os tutorados tem nos processos de socialização. O primeiro elemento evidenciado tem a ver com a função do tutor que, nas entrevistas, foi definido como uma pessoa que contribui com o desenvolvimento formativo dos estudantes que lhe são entregues. Nas entrevistas evidencia-se uma quase total ausência da utilização, por parte dos tutores, das palavras "deficiente" e "com deficiências". Depois de ter encontrado os seus tutorados, os tutores parecem concentrados exclusivamente na relação com os tutorados, nas atividades a desenvolver, e descuidam das questões ligadas à deficiência. A partir da análise dos dados, a relação tutor/tutorado parece focalizada nos objetivos comuns e nas praxes educacionais a serem implementadas, anulando de tal forma a percepção da diversidade. As entrevistas ilustram que o tutor é uma pessoa que constantemente apoia e estimula, individualizando ao máximo as metodologias de ensino/aprendizagem, a fim de favorecer o aumento da autoestima dos seus tutorados.

Todavia esta relação de aprendizagem acontece numa ligação afetiva amistosa simétrica, na qual o tutorado ganha competências e segurança enquanto o tutor ganha simetricamente as mesmas coisas.

O conceito de integração, porém, oferece-nos uma reflexão sobre o "sujeito" que deve ser integrado. Quando se fala de integração, de fato, refere-se muitas vezes a uma diversidade que deve ser integrada e acolhida num contexto cultural pré-definido. Neste caso, os estudantes universitários "normais" devem perceber e aproximar-se à diversidade do estudante com deficiências que, por sua vez, deve tentar inserir-se num sistema educacional de práticas e relações que nascem e se construem sem ter em conta, na maioria das vezes, a multiplicidade das "diferenças". Esta ótica não só produz preconceitos e estereótipos, como também implementa uma ideia de "assistência" e de "dependência", que dificilmente pode garantir uma verdadeira integração. Esta exige uma troca que se realiza, pelo contrário, em relações recíprocas e interdependentes. O tutoramento entre pares, de fato, pode revelar-se, como se evidencia neste trabalho, uma metodologia apta a desenvolver uma relação na qual se realiza uma troca recíproca de competências, dentro de uma relação afetiva e simétrica.

revista entreideias, Salvador, v. 2, n. 2, p. 201-216, jul./dez. 2013213 
Isso permite ultrapassar a ótica assistencial e devolve poder aos próprios protagonistas da relação.

Em conclusão, de acordo com as teorias da psicologia social e cultural, o tutor parece capaz de incitar o tutorado para que "ultrapasse a si mesmo", facilitando a sua aprendizagem e ativando assim a sua "zona de desenvolvimento proximal" (BRUNER, 1986, 1990, 1991; ROGOFF, 1995; VYGOTSKIJ, 1934)

Com certeza que os futuros percursos de pesquisas serão destinados a recolher o ponto de vista dos tutorados, mesmo de faculdades diferentes daquela de ciências da formação, onde se pode hipotetizar que os tutores tenham, devido ao seu percurso de formação e de orientação profissional, uma maior ou simplesmente uma diferente sensibilidade acerca do assunto da deficiência.

\title{
Peer tutoring and college integration of disability
}

\begin{abstract}
The study explores the relationship between peer-tutor and disabled tutee in the university context. The hypothesis of research is that the peer tutoring method can facilitate the integration of university students affected by disability and that the sharing of problems and of a similar condition between peer-tutors and tutees can facilitate their process of mutual socialization. We have administered a questionnaire to 20 tutors, and the resulting narrative corpus was submitted to a textual analysis. The results underline the peer tutoring as a valid methodology for the creation of mutual competence relationships, within an affective and symmetrical context; it allows to overcome the assistance perspective often associated to disability, and encourages the tutee to "to push his/her own limits", facilitating his/her learning processes and thus activating his/her "proximal development zone".
\end{abstract}

Keywords: Relationships. Integration. Peer tutoring.

\section{Referências}

ANOLLI, L. Psicologia della cultura. Bologna: Il Mulino, 2005.

BERGER, P. L.; LUCKMANN, T. La realtà come costruzione sociale. Bologna: Il Mulino, 1966.

BRUNER, J. Actual minds, possible words. Cambridge Mass.: Harvard University Press, 1986.

BRUNER, J. Acts of meaning. Cambridge, Mass.: Harvard University Press, 1990.

BRUNER, J. S. The ontogenesis of speech acts. Journal of Child Language, v. 2, p. 1-40, 1975.

BRUNER, J. S. Child's Talk: Learning to use Language. Oxford: Oxford University Press, 1983. 
BRUNER, J. S. Presentazione. In: IANNACCONE, A. (Ed.). Le condizioni sociali del pensiero. Milano: Unicopli, 2010.

BRUNER, J. S. The narrative construction of reality. Critical Inquiry, v. 18, n. 1, p. 1-21, 1991.

COLE, M. Cultural Psychology. Cambridge, Mass.: Harvard University Press, 1996.

COLVIN, J. W. Peer tutoring and social dynamics in higher education. Mentoring \& Tutoring, v. 15, n. 2, p. 165-181, 2007.

DEMETRIO, D. Filosofia dell'educazione ed età adulta. Simbologie, miti e icone narrative. Torino: UTET, 2003.

ERIKSON, E. Identity: Youth and Crisis. New York: Norton1968.

FLACHIKOV, N. Learning Together: Peer Tutoring. Higher Education Routledge, UK, 2012.

GERGEN, K. J. Social Construction and the Educational Process. In: STEFFE, L. P.; GALE, J. (Ed.). Constructivism in education. Hillsdale, New Jersey: Lawrence Erlbaum, 1995. p. 17-39.

GORDON, E. E. Peer tutoring: A Teacher's Resource Guide. Lanham, MarYland: Scarecrow Press, 2005.

IANES, D. Didattica speciale per l'integrazione. Trento: Erickson, 2000.

IANNACCONE, A.; SMORTI, A. "Editoriale". Psicologia Cultural,. Roma, gennaio/giugno 2009.

LANCIA, F. Strumenti per l'analisi dei testi. Introduzione all'uso di T-LAB. Milano: Franco Angeli, 2005.

PARKIN, S., MCKEGANY, N. The rise and rise of peer education approaches. Drugs: Education, Prevention and Policy, v. 7, n. 3, p. 293310, 2000.

PARLAMENTO ITALIANO. Legge 17/1999, Nuovi interventi a favore degli studenti universitari in situazione di handicap. Site: http://www. parlamento.it/parlam/leggi/990171.htm

ROGOFF, B. Observing, socio-cultural activity on three planes:

Participatory appropriation, guided participation and apprenticeship. In: WERSCH, J. V.; P. DEL RIO, P.; ALVAREZ, A. (Ed.). Sociocultural studies of mind. Cambridge: Cambridge University Press, 1995. p. 139164.

SALVATORE, S. et al. Sociocostructivism and theory of the unconscious. A Gaze over Research Horizon. European Journal of School Psychology, v. 1, n. 1, p. 9-36, 2003.

SHIMA, I.; RODRIGUES, R. The Implementation of EU Social Inclusion and Social Protection Strategies in European Countries with Reference to Equality for Disabled People. Leeds: University of Leeds, 2009. Report prepared for the Academic Network of European Disability experts.

revista entreideias, Salvador, v. 2, n. 2, p. 201-216, jul./dez. 2013215 
SKOWRONSKI, J. J; WALKER, W. R. How describing autobiographical events can affect autobiographical memories. Social Cognition, v. 22, n. 5, p. 555-590, 2004.

SMORTI, A. Il Sé come testo. Firenze: Giunti, 1997.

SMORTI, A. La psicologia culturale. Roma: Carocci, 2003.

SORESI S. Psicologia dell'handicap e della riabilitazione. Bologna: Il Mulino, 1998.

VYGOTSKIJ, L. S. Pensiero e linguaggio. Bari: Laterza, 1934.

WYNNE, R.; MCANANEY, D. Active inclusion of young people with disabilities or health problems: background paper. Luxembourg: European Foundation for the Improvement of Living and Working Conditions, 2010 .

ZORFASS, J. Supporting students with learning disabilities: Integrating technology into an I-Search Unit. Technology and Disability, v. 3, n. 2, p. 129-136, 1994.

Recebido: 22/04/2013 | Aprovado: 26/08/2013 